\title{
Updates of colorectal cancer liver metastases therapy: review on DEBIRI
}

\author{
Giammaria Fiorentini* ${ }^{*, 1}$ (D), Donatella Sarti ${ }^{1}$, Roberto Nani $^{2}$, Camillo Aliberti ${ }^{3}$, Caterina \\ Fiorentini ${ }^{4} \&$ Stefano Guadagni ${ }^{5}$ \\ ${ }^{1}$ Onco-Hematology Department, Azienda Ospedaliera 'Ospedali Riuniti Marche Nord', 61122 Pesaro, Italy \\ ${ }^{2}$ Department of Radiology, University Milano Bicocca, ASST Papa Giovanni XXIII, Piazza OMS - Organizzazione Mondiale della \\ Sanità 1, 24127 Bergamo, Italy \\ ${ }^{3}$ Oncology Radiodiagnostics Department, Oncology Institute of Veneto, Institute for the Research \& Treatment of Cancer, 35128 \\ Padova, Italy \\ ${ }^{4}$ Department of Medical Biothecnologies, Division of Cardiology, University of Siena, 53100 Siena, Italy \\ ${ }^{5}$ Department of Applied Clinical Sciences \& Biotechnology, Section of General Surgery, University of L'Aquila, via Vetoio 67100 \\ L'Aquila, Italy \\ *Author for correspondence: Tel.: +39 0721 364124; Fax: +39 0721 364094; g.fiorentini@alice.it
}

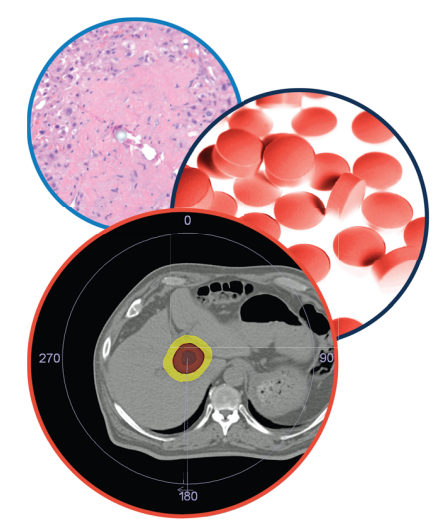

Hepatic Oncology

Colorectal cancer is a worldwide public health issue, presenting an advanced stage at diagnosis in more than $20 \%$ of patients. Liver metastases are the most common metastatic sites and are not indicated for resection in $80 \%$ of cases. Unresectable colorectal cancer liver metastases that are refractory to systemic chemotherapy may benefit from transarterial chembolization with irinotecan-loaded beads (DEBIRI). Several studies show the safety and efficacy of DEBIRI for the treatment of colorectal cancer liver metastases. The development of transarterial chembolization and the introduction of new embolics have contributed to better outcomes of DEBIRI. This article reviews the current literature on DEBIRI reporting its use, efficacy in terms of tumor response and survival and side effects.

First draft submitted: 19 September 2019; Accepted for publication: 19 December 2019; Published online: 21 January 2020

Keywords: colorectal cancer $\bullet C R C-L M \bullet D E B I R I \bullet$ liver metastases $\bullet$ liver resection

\section{DEBIRI for colorectal cancer liver metastases treatment}

Despite the introduction of new chemotherapeutic agents and the development of locoregional therapies (embolization, percutaneous ablation, hepatic arterial-directed infusion chemotherapy, internal radiation) that have contributed to better outcomes for colorectal cancer liver metastases (CRC-LM) [1,2], there is still a lack of standardized evidence-based protocols for optimal CRC-LM management [3].

Conventional transarterial chembolization (cTACE) with lipiodol has positive results for the treatment of hepatocellular carcinoma (HCC) [4] and for CRC-LM when used in combination therapies. Clinical indications for DEBIRI according to European Society fo Medical Oncology and National Comprehensive Cancer Network [1] are: presence of advanced disease that is not indicated to surgery and/or refractory to systemic therapy, Eastern Cooperative Oncology Group 2, Child-Pugh B, Barcelona Clinic Liver Cancer C, normal hematological values, ALT and GGT $<3 \times$ upper limit of normal levels; total bilirubin $<2.5 \mathrm{mg} / \mathrm{m}$. [5-8]. This indication is confirmed by several studies and recent reviews [1,2,7,8]. European Society for Medical Oncology

The comparison of hepatic arterial therapies (radioembolization and TACE) in CRC-LM patients shows a similar median overall survival (OS) of 15.2 months [6], suggesting their positive efficacy in these patients. More recently, there has been an increasing use of TACE with irinotecan-loaded drug eluting beads (DEBIRI) in the treatment of CRC-LM [7-9]. This article reviews the current literature on DEBIRI reporting its use, efficacy in terms of tumor response and survival and side effects.

\section{DEBIRI: mechanism \& function}

The use of drug eluting beads (DC-Beads) for the intra-arterial delivery of irinotecan was introduced in early 20th century for the treatment of CRC-LM [10-17]. DEBIRI involves the delivery of DC-Beads inside the hepatic artery

Future $\because$ Medicine 
of the lobe mainly affected by tumor metastases. TACE is also used in patients with bilobar disease, alternating the lobe in individual treatments. The tumor specificity of DEBIRI is given by the presence of a richer vascularity inside the tumor than in the normal liver tissue [18]. DEBIRI efficacy has been confirmed by several studies showing high percentage of tumor response [10-17].

DEBIRI selectivity, however, is different from that of TACE with doxorubicin in HCC. This may be due to the different loco regional activity of irinotecan and the necrotic activity of doxorubicin [19]. The irinotecan is rapidly released from DC-Beads inside tumor metastases, reducing significantly the systemic exposure to the drug and increasing its local concentration. DC-Beads, moreover, occlude liver arterial vessels, increasing the selectivity for tumor tissue that is supplied mainly by hepatic arterial circulation. The normal liver tissue, on the contrary, is mainly supplied by the portal vein and is not affected by the ischemia induced by TACE, as shown in animal models [20]. The ischemic effect alone is not enough to justify the extent of tumor response observed but also the irinotecan effect is required. The use of DC-Beads alone, indeed, results in a lower tumor response than that obverted in a dose-dependent manner of DEBIRI, confirming the importance of both embolization and drug activity [21]. Another important result of embolization-induced ischemia is the rapid decrease of liver $\mathrm{pH}$ that activate irinotecan [22].

\section{DEBIRI activity \& clinical application}

Type \& size of the embolics

There are several types of embolics for the irinotecan delivery. Recent improvements of TACE, including the introduction of new types of embolics (PEG microspheres), have increased tumor response in CRC-LM patients [23,24]. Some type of beads (LUMI) incorporate an imaging agent and can be loaded with a chemotherapeutic drug and can be visualized during TACE and in follow-up imaging [25-27].

The available beads diameters are different and can be selected according to tumor size and vascularization. At first, the DC-Beads of 100-300 $\mu \mathrm{m}$ were the most used [16], later the 70-150 $\mu \mathrm{m}$ DC-Beads M1 were introduced [28] because of the hypo vascularity of CRC-LM. The smaller diameter allowed a more distal penetration of the beads [29], allowing a higher concentration of irinotecan administered inside the tumor and fewer adverse events [30]. A comparison between DEBIRI performed using DC-Beads with small $(70-150 \mu \mathrm{m})$ versus big (100$300 \mu \mathrm{m})$ diameter showed that small beads delivered significantly $(\mathrm{p}>0.005)$ a higher drug concentration (96\%) inside the target than the big beads (79\%) and a complete stasis in a lower number of TACE in CRC-LM patients $(p<0.005)[31,32]$. This result was further supported by the pharmacokinetic study of irinotecan release from small and big size DC-Beads that showed an advantage for small size beads as concerning the maximum concentration of irinotecan observed in the target area and low adverse events [33]. This effect may be due to a higher surface area/volume associated with DC-Beads M1. However, the 100-300 $\mu \mathrm{m}$ beads remain the most used size (Table 1).

The DC-Beads $40 \mu \mathrm{m}$ diameter embolic microspheres were recently introduced for DEBIRI, resulting in small toxicity and good efficacy: local tumor control of $88.9 \%$, median liver progression-free survival (PFS) of 5.9 months and median OS of 13.5 months [38].

DC-Beads are loaded with irinotecan. Irinotecan molecule terminates in an open-ring carboxylate that is converted to a closed-ring lactone (active form) in a pH-dependent manner [21]. This latter form binds better to the sulfonate groups that are present in the DC-Beads [21]. Irinotecan is loaded to the beads in a prodrug form and is activated by carboxylesterase that are present in several parts of the body, such as gut, liver and blood [21]. The activated drug can bind to its target (TOPO-1) 1000-times stronger than the inactive form and interferes with DNA replication, resulting in single strand breaks in DNA and hence, apoptosis of the tumor cell [21].

\section{DEBIRI-related side effects}

Due to the local delivery of irinotecan, DEBIRI does not induce dose-dependent side effects (neutropenia and diarrhoea) that are generally observed as a consequence of the systemic administration [13-16]. The adverse events commonly observed after TACE are fever without associated sepsis, pain in the right upper quadrant, pain due to capsular starching associated with postinterventional reaction and swelling, nausea and/or vomiting (Table 1) [39]. These symptoms are referred to as postembolization syndrome. Right upper quadrant pain is the most discomforting adverse event, in particular during the beads injection. Incidence of adverse events correlated to DEBIRI varies between different studies, median incidence is $57 \%$ for nonserious adverse event and $11 \%$ for serious adverse events (Tables $2 \& 3$ ). 


\begin{tabular}{|c|c|c|c|c|c|c|c|c|}
\hline Study (year) & Patients (n) & $\begin{array}{l}\text { Intra-arterial } \\
\text { support therapy }\end{array}$ & Embolic type & $\begin{array}{l}\text { Embolic } \\
\text { diameter } \\
(\mu \mathrm{m})\end{array}$ & $\begin{array}{l}\text { Average } \\
\text { irinitecan } \\
\text { dosage }(\mathrm{mg})\end{array}$ & Type of adverse event & Peri-procedural therapy & Ref. \\
\hline $\begin{array}{l}\text { Fiorentini } \\
\text { et al. (2017) }\end{array}$ & 50 & Lidocaine & LP & 100 & 200 & $\begin{array}{l}\text { Pain } 16(32 \%) \\
\text { Fever } 7(14 \%) \\
\text { Hypertransaminasemia } 10 \\
(20 \%)\end{array}$ & $\begin{array}{l}\text { Intravenous hydration } \\
10 \mathrm{mg} \text { morphine } \\
2 \mathrm{mg} \text { ondasentron } \\
400 \mathrm{mg} \text { Ciprofloxacin } \\
\text { Paracetamol in the case of } \\
\text { fever }\end{array}$ & [23] \\
\hline $\begin{array}{l}\text { Ranieri et al. } \\
\text { (2016) }\end{array}$ & 25 & No & HS & $100-300$ & $100-200$ & $\begin{array}{l}\text { Pain } 22 \% \\
\text { Hypertension } 30 \% \\
\text { Fever } 16 \% \\
\text { Hypertransaminasemia } \\
69 \%\end{array}$ & $\begin{array}{l}\text { Intravenous hydration } \\
\text { Morphine } \\
\text { Antiemetic and antibiotic } \\
\text { prophylaxis } \\
\text { Morphine post-procedure }\end{array}$ & [34] \\
\hline $\begin{array}{l}\text { Stutz et al. } \\
\text { (2015) }\end{array}$ & 27 & No & DC & $\begin{array}{l}100-300 \\
300-500\end{array}$ & $50-200$ & $\begin{array}{l}\text { Nausea } 8(30 \%) \\
\text { Vomiting } 6(22 \%) \\
\text { Right upper quadrant Pain } \\
5(59 \%) \\
\text { Fatigue } 9(33 \%) \\
\text { Ascites } 6(22 \%)\end{array}$ & $\begin{array}{l}\text { Antiemetics } \\
\text { Antibiotics and standards } \\
\text { protocol for right upper } \\
\text { quadrant pain prevention }\end{array}$ & [35] \\
\hline $\begin{array}{l}\text { Fiorentini } \\
\text { et al. (2015) }\end{array}$ & 40 & Lidocaine & DC & $\begin{array}{l}100-300 \\
300-500\end{array}$ & 200 & $\begin{array}{l}\text { PES } 20(30 \%) \\
\text { Gastritis } 6(15 \%) \\
\text { Dehydration (G2) } 2(5 \%) \\
\text { Cholecystitis (G3) } 1(2.5 \%) \\
\text { Hypertension (G2) } 7(17.5 \\
\%)\end{array}$ & $\begin{array}{l}\text { Intravenous hydration } \\
10 \mathrm{mg} \text { morphine } \\
2 \mathrm{mg} \text { ondasentron } \\
400 \mathrm{mg} \text { Ciprofloxacin } \\
\text { Paracetamol in case of } \\
\text { fever }\end{array}$ & [36] \\
\hline $\begin{array}{l}\text { Eichler et al. } \\
\text { (2012) }\end{array}$ & 25 & Lidocaine & DC & $\begin{array}{l}100-300 \\
300-500\end{array}$ & 73 & $\begin{array}{l}\text { Nausea } 8(30 \%) \\
\text { Vomiting } 6(22 \%) \\
\text { Right upper quadrant Pain } \\
17(59 \%) \\
\text { Fatigue } 9(33 \%) \\
\text { Ascites } 6(22 \%)\end{array}$ & $\begin{array}{l}\text { Pethidine } \\
\text { Granisentron }\end{array}$ & [37] \\
\hline $\begin{array}{l}\text { Fiorentini } \\
\text { et al. (2012) }\end{array}$ & 36 & Lidocaine & DC & $\begin{array}{l}100-300 \\
300-500\end{array}$ & 200 & $\begin{array}{l}\text { Pain } 30 \% \\
\text { Vomiting 25\% } \\
\text { Diarrhea 2\% } \\
\text { Asthenia 20\% } \\
\text { Leukopenia 5\% } \\
\text { Anaemia 5\% } \\
\text { Fever 15\% } \\
\text { Alopecia 5\% }\end{array}$ & $\begin{array}{l}\text { Intravenous hydration } \\
10 \mathrm{mg} \text { morphine } \\
2 \mathrm{mg} \text { ondasentron } \\
400 \mathrm{mg} \text { Ciprofloxacin } \\
\text { Paracetamol in case of } \\
\text { fever }\end{array}$ & [16] \\
\hline
\end{tabular}

DC: Drug eluting bead (Biocompatibles, Farnham, UK); HS: HepaSphere (BioSphere Medical, Roissy-en-France, France); LP: LifePearl (Terumo, Leuvent, Belgium); ND: Not declared; PES: Postembolic syndrome.

There are different opinions concerning the origin of this type of pain. At first it was deemed the irinotecan responsible for pain, however, the systemic infusion of irinotecan does not cause pain [12]. Another hypothesis is that the swelling induced by the osmotic alteration correlated to the loading solution of the beads, however, intrahepatic infusion of irinotecan at high concentration does not cause pain [10-12,14].

In some cases, the origin of pain may be due to the mislocalization of the beads that are not delivered inside the target but reach extra target tissues such as the cholecystis as the result of patients' arterial vessel anomalies [39]. The introduction of radiopaque DC Beads LUMI ${ }^{\mathrm{TM}}$ allows to rapidly detect the mislocalization and to prevent the correlated adverse event.

Notwithstanding the unclear origin of pain, it can be prevented with supportive therapy with morphine and intraarterial lidocaine that are administered before the TACE, and antibiotic/antiemetic prophylaxis and intravenous hydration before and after the procedure [39].

In the past decade, several efforts have been made to improve TACE tolerability, including drug dosage adjustments, incremental experience of interventional radiologist, introduction of new type of drugs and microspheres to obtain a more precise and selective treatment $[23-27]$.

\section{Support therapy protocol for DEBIRI}

From 2006, Fiorentini and colleagues developed a pre- and post-procedural supportive therapy to prevent and limit acute toxic effects correlated to the DEBIRI procedure. This protocol includes a careful therapy with morphine and intra-arterial lidocaine that are administered before the DEBIRI, and antibiotic/antiemetic prophylaxis and 
Table 2. DEBIRI results in prospective single arm studies.

\begin{tabular}{|c|c|c|c|c|c|c|c|c|}
\hline Study & Aims & Prior CHT & Patients (n) & os & PFS & AE & SAE & Ref. \\
\hline $\begin{array}{l}\text { Aliberti et al. } \\
\text { (2011) }\end{array}$ & Safety & Yes & 82 & 25 months & TTP 8 months & $N / A$ & $25 \%$ & [40] \\
\hline $\begin{array}{l}\text { Martin } \\
\text { et al. (2011) }\end{array}$ & Safety efficacy & Yes & 55 & 19 months & 11 months & 28 in 99 sessions & 7 in 99 sessions & [41] \\
\hline $\begin{array}{l}\text { Eichler } \\
\text { et al. (2012) }\end{array}$ & Safety & Yes & 11 & $\mathrm{~N} / \mathrm{A}$ & TTP 5.1 months & 43 in 9 sessions & None & [37] \\
\hline $\begin{array}{l}\text { Martin } \\
\text { et al. (2012) }\end{array}$ & Safety & No & 10 & $\mathrm{~N} / \mathrm{A}$ & $\mathrm{N} / \mathrm{A}$ & 99 in 10 PTS & 4 in 40 PTS & [42] \\
\hline lezzi et al. (2015) & Safety efficacy & Yes & 20 & 7.3 months & 4 months & 64 in 54 sessions & 2 in 54 sessions & [43] \\
\hline $\begin{array}{l}\text { Pellerin } \\
\text { et al. (2019) }\end{array}$ & Efficacy & No & 57 & 33 months & 10.8 months & $\begin{array}{l}\mathrm{G} 2 \\
10-25 \%\end{array}$ & $\begin{array}{l}\text { G3-4 } \\
5-9 \%\end{array}$ & [44] \\
\hline $\begin{array}{l}\text { Martin } \\
\text { et al. (2015) }\end{array}$ & Safety efficacy & Yes & 30 & $\mathrm{~N} / \mathrm{A}$ & $N / A$ & 19 in 57 sessions & 3 in 57 sessions & [42] \\
\hline $\begin{array}{l}\text { Bhutiani } \\
\text { et al. (2016) }\end{array}$ & Safety efficacy & Yes & 296 & $\begin{array}{l}88 \% \text { at } \\
12 \text { months }\end{array}$ & $\mathrm{N} / \mathrm{A}$ & 105 in 666 sessions & 30 in 666 sessions & [45] \\
\hline $\begin{array}{l}\text { Akinwande } \\
\text { et al. (2016) }\end{array}$ & $\begin{array}{l}\text { Safety efficacy } \\
70-150 \mu \mathrm{m}\end{array}$ & Yes & 15 & 13 months & $\mathrm{N} / \mathrm{A}$ & 2 in 32 sessions & None & [32] \\
\hline $\begin{array}{l}\text { Scevola } \\
\text { et al. (2017) }\end{array}$ & Safety efficacy & Yes & 62 & $\begin{array}{l}27,5 \% \text { at } \\
51 \text { months }\end{array}$ & $\mathrm{N} / \mathrm{A}$ & 79 in 174 sessions & None & [46] \\
\hline
\end{tabular}

AE: Adverse event; CHT: Chemotherapy; G: Grade; IRI: Irinotecan; N/A: Not applicable; OS: Overall survival; PFS: Progression-free survival; PTS: Patient; SAE: Serious adverse event; TTP: Time to progression.

\section{Table 3. DEBIRI results in randomized controlled studies.}

\begin{tabular}{|c|c|c|c|c|c|c|c|c|}
\hline Study & Aims & Prior $\mathrm{CHT}$ & Patients (n) & os & PFS & AE G1-2 & SAE G3-4 & Ref. \\
\hline $\begin{array}{l}\text { Fiorentini et al. } \\
(2012)\end{array}$ & DEBIRI vs FOLFIRI & Yes & 74 & $\begin{array}{l}22 \text { vs } 15 \text { months } \\
(p=0.031)\end{array}$ & $\begin{array}{l}7 \text { vs } 4 \text { months } \\
(p=0.006)\end{array}$ & 14 vs $18 \%$ & 2 vs $4 \%$ & [16] \\
\hline $\begin{array}{l}\text { Martin et al. } \\
(2015)\end{array}$ & $\begin{array}{l}\text { FOLFOX }+/- \\
\text { Beva }+ \text { DEBIRI vs } \\
\text { FOLFOX }+/- \text { Beva }\end{array}$ & No & 70 & $\begin{array}{l}\text { Not reached at } \\
\text { publication time }\end{array}$ & $\begin{array}{l}15 \text { vs } 12 \text { months } \\
(p>0.05)\end{array}$ & 973 vs 459 & 57 vs 15 & [42] \\
\hline $\begin{array}{l}\text { Fiorentini } \\
\text { et al. (2019) }\end{array}$ & $\begin{array}{l}\text { DEBIRI vs } \\
\text { DEBIRI + BEVA }\end{array}$ & Yes & 30 & 5.8 vs 12 months & 4 vs 6 months & 12 vs 16 & None & [47] \\
\hline
\end{tabular}

AE: Adverse event; BEVA: Bevacizumab; CHT: Chemotherapy; G: Grade; OS: Overall survival; PFS: Progression-free survival; SAE: Serious adverse event.

intravenous hydration before and after the procedure. This protocol allows a tolerability of $90 \%[13-16,23,24]$ The cardiac evaluation with echocardiography did not reveal any significant variation before and after last TACE [23,24]. Hence DEBIRI could be considered safe as concerning the cardiac profile, unless in presence of concomitant heart disease.

The analysis of the literature shows that only few studies detail the protocol of supportive therapy for patients that undergo TACE [34-37,48-50]. Ranieri and colleagues, for example, administer intravenous hydration, antiemetic and antibiotic prophylaxis, and morphine to reduce post embolic syndrome. Morphine is also administered in the postprocedure period [34].

All patients were treated according to hospital procedure for TACE; routine prophylactic treatments against nausea and vomiting, infection and upper right quadrant pain were also given to patients prior to the procedure. These included antiemetic medications as well as antibiotics and were given prior to TACE procedures (Table 3) [35].

General recommendations to avoid pain are: to explain the procedure very well to the patient and their family; to create a welcoming and calm environment in the IR room; to adopt periprocedural medications and lidocaine IA; to perform Lobar Infusion, to avoid the complete flow block; to perform a slow infusion for $1 \mathrm{~min}$ for $1 \mathrm{ml}$ of solution; to shake the syringe to keep the beads in suspension; to stop and restart the TACE if pain appears, without hurry; not to perform control angiogram because this causes beads to move out of the target; to carefully monitor the patient after TACE.

\section{Radiological assessment \& tumor response evaluation after DEBIRI in CRC-LM}

The radiological study of CRC-LM is required for the assessment of tumor response and can be done using MRI, computed tomography (CT) and positron emission tomography (PET) scan [51]. Specificity for the detection of 


\begin{tabular}{|c|c|c|c|c|c|}
\hline Study & Patients (n) & Responders (CR+PR) mRECIST (\%) & PFS (months) & OS (months) & Ref. \\
\hline Aliberti et al. (2011) & 82 & 78 & 8 & 25 & [40] \\
\hline Akinwande et al. (2014) & 149 & 40 & 7 & 13 & [69] \\
\hline Bhutiani et al. (2016) & 212 & 53 & NR & NR & [45] \\
\hline Eichler et al. (2012) & 11 & 22 & 5 & NR & [37] \\
\hline Fiorentini et al. (2015) & 40 & 50 & 9.8 & 20.4 & [36] \\
\hline Huppert et al. (2014) & 29 & 72 (EASL) & 5 & 8 & [70] \\
\hline lezzi et al. (2015) & 20 & 10 & 4 & 7.3 & [43] \\
\hline Martin et al. (2011) & 55 & 65 & 11 & 19 & [41] \\
\hline Nayaranan et al. (2013) & 28 & 45 & 4 & 13.3 & [71] \\
\hline Fereydooni et al. (2018) & 14 & 69.23 & NR & 18.14 & [33] \\
\hline Pellerin et al. (2019) & 57 & 73.2 & 10.8 & 33.1 & [44] \\
\hline
\end{tabular}

CR: Complete response; EASL: European Association for the Study of the Liver; OS: Overall survival; PFS: Progression-free survival; PR: Partial response.

liver metastases of CT, MRI and PET is very high: 95, 93, 97\%, respectively [52]. CT scans, however, are not always adequate as radiological tool to assess tumor response of DEBIRI [53]. MRI with liver-specific contrast agents has a higher sensitivity, especially when underlying liver diseases (steatosis, cirrhosis) are present or for the identification of very small lesions $(<1 \mathrm{~cm})$, and for this reason it is better than CT [54]. PET scan allows to obtain whole body map and a recent study shows that it is the best radiological method for the assessment of liver metastases from gastrointestinal tumors, even if it can have high false negative rates in patients recently treated with chemotherapy [55,56]. PET scan can be associated to CT scan thus improving the sensitivity up to 97\% [52].

Tumor response evaluation is very important in patients with liver tumor that are treated with DEBIRI. The Tumor response-Response Evaluation Criteria in Solid Tumors (RECIST) and WHO has been used since early nineties for tumor response evaluation in clinical trials [57-60]. The European Association for the Study of the Liver (EASL) and the European Organization for Research and Treatment of cancer has formulated Clinical Practice Guidelines. These guidelines establish that tumor assessment should be done using Modified Tumor responseResponse Evaluation Criteria in Solid Tumors (mRECIST) to assess CT or MRI done 4 weeks after treatment. Conventional RECIST criteria are based on tumor shrinkage to measure tumor response. TACE and TARE, however, induce tumor damage and for this reason, there can be tumor response even if the tumor size is the same. The reduction in viable tumor is a better way to estimate tumor response in these cases and for this reason, RECIST criteria was modified [59].

The mRECIST has been recently introduced to overcome the limitations of RECIST and now it is the most used method to assess tumor response in CRC-LM after DEBIRI treatment $[34,35,48,49]$. This method assesses tumor response as identification of intratumoral necrotic areas and reduction of tumor burden in triphasic CT or MRI [61]. Other modifications of the RECIST include monitoring of vascular invasion, lymph nodes, ascites, pleural effusion and presence of new lesions [62,63].

\section{DEBIRI in combination therapies}

DEBIRI can be associated to systemic therapies to target extrahepatic diseases. The combination of DEBIRI with chemotherapy based on FOLFOX with or without bevacizumab has limited toxicity and higher overall response $[64,65]$. The combination DEBIRI-FOLFOX or FOLFIRI is also successful for unresectable CRC-LM therapy [66,67]. DEBIRI in association with capecitabine can be used in heavily pretreated patients with positive tolerability and tumor response rates [68]. Also the combination DEBIRI + Cetuximab is safe and active [36].

\section{DEBIRI efficacy}

Cumulative results from single arm studies [40-46,69-72] on DEBIRI show that the median OS is 18 months (range 7.3-25) and 33 months when DEBIRI is combined to FOLFOX 6 (Table 4). Median PFS is 6.7 months (range 4-11) and 10.8 months when DEBIRI is combined to FOLFOX 6 (Table 4). As concerning the tumor response, median overall response rate was $62 \%$ (range $10-78 \%$; Tables $2-4$ ). 
Other studies, according to the method used for tumor response evaluation (RECIST vs mRECIST/EASL), report an objective tumor response ranging between 56.2 and $51.1 \%$ [7-9]. These data further support the beneficial effect of DEBIRI for the treatment of CRC-LM.

\section{Predictive factors}

Survival according to clinical and molecular characteristics of patients can be correlated to CEA level and it could be used as biomolecular prognostic marker in CRC-LM patients treated with DEBIRI [68]. A study monitoring CEA and CA19.9 levels in CRC-LM patients after DEBIRI find an interesting correlation between longer survival and significant CEA level reduction ( $\geq 20 \%$ ), however, the correlation between CEA reduction and tumor response was not statistically significant [68]. If these data are confirmed by further studies with a larger number of patients, DEBIRI could be interrupted in case of CEA levels stability after the first treatment, in order to avoid further sessions that could be not effective.

Another potential biomarker for predicting treatment efficacy and risk of adverse events after DEBIRI is VEGFR1. A recent study monitored the VEGF/R1/R2 levels in colorectal cancer patients after TACE treatment [33]. They showed a decreased VEGFR1 level, but not VEGF and VEGFR2 at 24 h post-treatment. This downregulation of VEGFR1 is associated with the antitumor effect of VEGF and may be correlated with better prognosis [33]. The potential prognostic value of VEGFR1, however, is not confirmed in a conclusive manner, further studies are required to address this issue.

\section{Conclusion}

DEBIRI is a promising intra-arterial approach that can be offered alone or in combination with systemic chemotherapy after failure of previous chemotherapy lines. cTACE with lipiodol has positive results for the treatment of HCC [4] and for CRC-LM when used in combination therapies [72]. One recent study on the palliative and neoadjuvant use (with subsequent thermal ablation) of cTACE in unresectable and chemoresistant CRC-LM reports a median OS and PFS of 12.6 and 5.9 months in the palliative setting and 25.8 and 10.8 months for the neoadjuvant use of cTACE [72]. This suggest that cTACE is a more effective treatment option in advanced nonresectable CRC-LM if associated to thermal ablation or other chemotherapeutics (MitomycinC, irinotecan) [72]. TACE can be used in both palliative and therapeutic settings.

DEBIRI is safe and effective for the treatment of unresectable CRC-LM. Irinotecan is a pro-drug and requires activation, occurring in normal liver parenchyma, for this reason lobar infusions should to be preferred. The $\mathrm{pH}$-dependent nature of irinotecan activation and the DEBIRI-induced tumor hypoxia is a unique mechanism of treatment. Periprocedural medications are available to control pain and do not reduce responses to DEBIRI.

Further randomized trials to determinate the ideal patient population, the best timing of treatment, the best techniques for beads delivery are warranted.

\section{Future perspective}

Patients with liver metastases from colorectal cancer are often unresectable and/or refractory to systemic therapy, for this reason they are indicated for locoregional therapy. DEBIRI is among the most used locoregional method and is safe and effective for the treatment of unresectable CRC-LM. DEBIRI can also be used as macro-antiangiogenic therapy. This effect can be further enhanced by the combination of DEBIRI with molecular antiangiogenic therapy, such as of bevacizumab, in order to reduce neo-angiogenesis embolization-induced. This could reduce also recurrences while increasing PFS and survival, optimizing the patient's care.

\section{Financial \& competing interests disclosure}

The authors have no relevant affiliations or financial involvement with any organization or entity with a financial interest in or financial conflict with the subject matter or materials discussed in the manuscript. This includes employment, consultancies, honoraria, stock ownership or options, expert testimony, grants or patents received or pending, or royalties.

No writing assistance was utilized in the production of this manuscript.

\section{Open access}

This work is licensed under the Attribution-NonCommercial-NoDerivatives 4.0 Unported License. To view a copy of this license, visit http://creativecommons.org/licenses/by-nc-nd/4.0/ 
- DEBIRI involves the delivery of DC-Beads inside the hepatic artery of the lobe mainly affected by tumor metastases.

- The tumor specificity of DEBIRI is given by the presence of a richer vascularity inside the tumor than in the normal liver tissue.

- DEBIRI efficacy has been confirmed by several studies showing high percentage of tumor response and improved overall survival.

- There are several types of embolics for the irinotecan delivery. Recent improvements of transarterial chembolization (TACE), including the introduction of new types of embolics (PEG microspheres), have increased tumor response in colorectal cancer liver metastases patients.

- The adverse events commonly observed after TACE are fever without associated sepsis, pain in the right upper quadrant, pain due to capsular starching associated with postinterventional reaction and swelling, nausea and/or vomiting.

- Supportive therapy protocol includes a careful therapy with morphine and intra-arterial lidocaine that are administered before the TACE, and antibiotic/antiemetic prophylaxis and intravenous hydration before and after the procedure.

- The Modified Tumor response-Response Evaluation Criteria in Solid Tumors (mRECIST) has been recently introduced to overcome the limitations of RECITS and now it is the most used method to assess tumor response in colorectal cancer liver metastases after DEBIRI treatment.

- The combination DEBIRI with FOLFOX, FOLFIRI or Cetuximab is successful for unresectable colorectal cancer liver metastases therapy and safe.

\section{References}

Papers of special note have been highlighted as: $\bullet$ of interest $\bullet \bullet$ of considerable interest

1. Gruber-Rouh T, Marko C, Thalhammer A et al. Current strategies in interventional oncology of colorectal liver metastases. Br. J. Radiol. 89(1064), 20151060 (2016).

2. Jones RP, Malik HZ, Fenwick SW et al. PARAGON II - a single arm multicentre phase II study of neoadjuvant therapy using irinotecan bead in patients with resectable liver metastases from colorectal cancer. Eur. J. Surg.Oncol. 42(12), 1866-1872 (2016).

- First study of DEBIRI as neoadjuvant therapy.

3. Levy J, Zuckerman J, Garfinkle R et al. Intra-arterial therapies for unresectable and chemorefractory colorectal cancer liver metastases: a systematic review and meta-analysis. HPB (Oxford) 20(10), 905-915 (2018).

4. Lo CM, Ngan H, Tso WK et al. Randomized controlled trial of transarterial lipiodol chemoembolization for unresectable hepatocellular carcinoma. Hepatology 35(5), 1164-1171 (2002).

5. Lammer J, Malagari K, Vogl T et al. Prospective randomized study of doxorubicin-eluting-bead embolization in the treatment of hepatocellular carcinoma: results of the PRECISION V study. Cardiovasc. Intervent. Radiol. 33(1), 41-52 (2010).

6. Zacharias AJ, Jayakrishnan TT, Rajeev R et al. Comparative effectiveness of hepatic artery based therapies for unresectable colorectal liver metastases: a meta-analysis. PLoS ONE 10(10), e0139940 (2015).

- Major metanalysis of hepatic artery therapies.

7. Akinwande O, Dendy M, Ludwig JM, Kim HS. Hepatic intra-arterial injection of irinotecan drug eluting beads (DEBIRI) for patients with unresectable colorectal liver metastases: a systematic review. Surg. Oncol. 26(3), 268-275 (2017).

-• Most important systematic review on DEBIRI.

8. Liu DM, Thakor AS, Baerlocher $\mathrm{M}$ et al. A review of conventional and drug-eluting chemoembolization in the treatment of colorectal liver metastases: principles and proof. Future Oncol. 11(9), 1421-1428 (2015).

- Interesting review on conventional chemoembolization.

9. Young S, D'Souza D, Flanagan S, Golzarian J. Review of the clinical evidence for the use of DEBIRI in the treatment of colorectal metastatic disease. Cardiovasc. Intervent. Radiol. 40(4), 496-501 (2017).

10. Fiorentini G, Poddie DB, Cantore $\mathrm{M}$ et al. Locoregional therapy for liver metastases from colorectal cancer: the possibilities of intraarterial chemotherapy, and new hepatic-directed modalities. Hepatogastroenterology 48(38), 305-312 (2001).

11. Fiorentini G, Rossi S, Bernardeschi P, Cantore M, Guadagni S. Is there a new drug beyond floxuridine for intra-arterial hepatic chemotherapy in liver metastases from colorectal cancer? J. Clin. Oncol. 23(9), 2105 (2005).

12. Fiorentini G, Rossi S, Dentico P et al. Irinotecan hepatic arterial infusion chemotherapy for hepatic metastases from colorectal cancer: a Phase II clinical study. Tumori 89(4), 382-384 (2003).

13. Aliberti C, Tilli M, Benea G, Fiorentini G. Trans-arterial chemoembolization (TACE) of liver metastases from colorectal cancer using irinotecan-eluting beads: preliminary results. Anticancer Res. 26(5B), 3793-3795 (2006). 
14. Fiorentini G, Aliberti C, Turrisi G et al. Intraarterial hepatic chemoembolization of liver metastases from colorectal cancer adopting irinotecan-eluting beads: results of a Phase II clinical study. In Vivo 21(6), 1085-1091 (2007).

15. Fiorentini G, Aliberti C, Benea G et al. TACE of liver metastases from colorectal cancer adopting irinotecan-eluting beads: beneficial effect of palliative intra-arterial lidocaine and post-procedure supportive therapy on the control of side effects. Hepatogastroenterology 55(88), 2077-2082 (2008).

16. Fiorentini G, Aliberti C, Tilli M et al. Intra-arterial infusion of irinotecan-loaded drug-eluting beads (DEBIRI) versus intravenous therapy (FOLFIRI) for hepatic metastases from colorectal cancer: final results of a Phase III study. Anticancer Res. 32(4), 1387-1395 (2012).

-• First randomized clinical trial on DEBIRI.

17. Martin RC, Joshi J, Robbins K, Tomalty D, O’Hara R, Tatum C. Transarterial chemoembolization of metastatic colorectal carcinoma with drug-eluting beads, irinotecan (DEBIRI): multi-institutional registry. J. Oncol. 2009, 539795 (2009).

18. Lencioni R, Aliberti C, De Baere T et al. Transarterial treatment of colorectal cancer liver metastases with irinotecan-loaded drug-eluting beads: technical recommendations. J. Vasc. Intervent. Radiol. 25(3), 365-369 (2014).

- Significant technical recommendations for DEBIRI.

19. Lencioni R, Baere T, Burrel M et al. Transcatheter treatment of hepatocellular carcinoma with doxorubicin-loaded DC Bead (DEBDOX): technical recommendations. Cardiovasc. Intervent. Radiol. 35(5), 980-985 (2012).

20. Taylor RR, Tang Y, Gonzalez MV, Stratford PW, Lewis AL. Irinotecan drug eluting beads for use in chemoembolization: in vitro and in vivo evaluation of drug release properties. Eur. J. Pharm. Sci. 30(1), 7-14 (2007).

-• First pharmacological study on irinotecan drug-eluting beads.

21. Lewis AL, Hall B. Toward a better understanding of the mechanism of action for intra-arterial delivery of irinotecan from DC Bead (DEBIRI). Future Oncol. 15(17), 2053-2068 (2019).

22. Brooks AJ, Hammond JS, Girling K, Beckingham IJ. The effect of hepatic vascular inflow occlusion on liver tissue $\mathrm{pH}$, carbon dioxide, and oxygen partial pressures: defining the optimal clamp/release regime for intermittent portal clamping. J. Surg. Res. 141(2), 247-251 (2007).

23. Fiorentini G, Carandina R, Sarti D et al. Polyethylene glycol microspheres loaded with irinotecan for arterially directed embolic therapy of metastatic liver cancer. World J. Gastroint. Oncol. 9(9), 379-384 (2017).

24. Aliberti C, Carandina R, Sarti D et al. Hepatic arterial infusion of polyethylene glycol drug-eluting beads for primary and metastatic liver cancer therapy. Anticancer Res. 36(7), 3515-3521 (2016).

25. Dreher MR, Sharma KV, Woods DL et al. Radiopaque drug-eluting beads for transcatheter embolotherapy: experimental study of drug penetration and coverage in swine. J. Vasc. Interv. Radiol. 23(2), 257-264 (2012).

26. Kilcup N, Tonkopi E, Abraham RJ, Boyd D, Kehoe S. Composition-property relationships for radiopaque composite materials: pre-loaded drug-eluting beads for transarterial chemoembolization. J. Biomater Appl. 30(1), 93-103 (2015).

27. Sharma KV, Dreher MR, Tang Y et al. Development of “imageable" beads for transcatheterembolotherapy. J. Vasc. Interv. Radiol. 21(6), 865-876 (2010).

28. Lewis AL, Dreher MR, O’Byrne V et al. DC BeadM1TM: towards an optimal transcatheter hepatic tumor therapy. J. Mater. Sci. Mater. Med. 27(1), 1-12 (2016).

29. Dreher MR, Sharma KV, Woods DL et al. Radiopaque drug-eluting beads for transcatheter embolotherapy: experimental study of drug penetration and coverage in swine. J. Vasc. Interv. Radiol. 23(2), 257-264 (2012).

30. Odisio BC, Ashton A, Yan Y et al. Transarterial hepatic chemoembolization with 70-150 $\mu \mathrm{m}$ drug-eluting beads: assessment of clinical safety and liver toxicity profile. J. Vasc. Interv. Radiol. 26(7), 965-971 (2015).

31. Akinwande OK, Philips P, Duras P, Pluntke S, Scoggins C, Martin RC. Small versus large-sized drug-eluting beads (DEBIRI) for the treatment of hepatic colorectal metastases: a propensity score matching analysis. Cardiovasc. Intervent. Radiol. 38(2), 361-371 (2015)

32. Akinwande O, Scoggins C, Martin RC. Early experience with 70-150 mum irinotecan drug-eluting beads (M1-DEBIRI) for the treatment of unresectable hepatic colorectal metastases. Anticancer Res. 36(7), 3413-3418 (2016).

33. Fereydooni A, Letzen B, Ghani MA et al. Irinotecan-eluting 75-150-mum embolics lobar chemoembolization in patients with colorectal cancer liver metastases: a prospective single-center Phase I study. J. Vasc. Interv. Radiol. 29(12), 1646-1653.e5 (2018).

34. Ranieri G, Niccoli A, Altini C et al. A pilot study employing hepatic intra-arterial irinotecan injection of drug-eluting beads as salvage therapy in liver metastatic colorectal cancer patients without extrahepatic involvement: the first southern Italy experience. Onco. Targets Ther. 9, 7527-7535 (2016).

35. Stutz M, Mamo A, Valenti D et al. Real-life report on chemoembolization using DEBIRI for liver metastases from colorectal cancer. Gastroenterol. Res. Pract. 2015, 715102 (2015).

36. Fiorentini G, Aliberti C, Sarti D et al. Locoregional therapy and systemic cetuximab to treat colorectal liver metastases. World J. Gastrointest. Oncol. 7(6), 47-54 (2015).

- One of the first locoregional therapy associated to systemic cetuximab. 
37. Eichler K, Zangos S, Mack MG et al. First human study in treatment of unresectable liver metastases from colorectal cancer with irinotecan-loaded beads (DEBIRI). Int. J. Oncol. 41(4), 1213-1220 (2012).

38. Mauri G, Varano GM, Della Vigna P et al. Transarterial embolization with small-Size particles loaded with irinotecan for the treatment of colorectal liver metastases: results of the MIRACLE III Study. Cardiovasc. Intervent. Radiol. 41(11), 1708-1715 (2018).

39. Aliberti C, Carandina R, Sarti D et al. Transarterial chemoembolization with DC Bead LUMI ${ }^{T M}$ radiopaque beads for primary liver cancer treatment: preliminary experience. Future Oncol. 13(25), 2243-2252 (2107).

40. Aliberti C, Fiorentini G, Muzzio PC et al. Trans-arterial chemoembolization of metastatic colorectal carcinoma to the liver adopting DC $\operatorname{Bead}(\mathrm{R})$, drug-eluting bead loaded with irinotecan: results of a phase II clinical study. Anticancer Res. 31(12), 4581-4587 (2011).

41. Martin RC, Joshi J, Robbins K et al. Hepatic intra-arterial injection of drug-eluting bead, irinotecan (DEBIRI) in unresectable colorectal liver metastases refractory to systemic chemotherapy: results of multi-institutional study. Ann. Surg. Oncol. 18(1), 192-198 (2011).

42. Martin RC, Scoggins CR, Schreeder M et al. Randomized controlled trial of irinotecan drug-eluting beads with simultaneous FOLFOX and bevacizumab for patients with unresectable colorectal liver-limited metastasis. Cancer 121(20), 3649-3658 (2015).

43. Iezzi R, Marsico VA, Guerra A et al. Trans-arterial chemoembolization with irinotecan-loaded drug-eluting beads (DEBIRI) and capecitabine in refractory liver prevalent colorectal metastases: a phase II single-Center study. Card. Interventional Radiol. 38(6), 1523-1531 (2015).

44. Pellerin O, Pernot S, Vidal V, Taieb J, Moussa N, Sapoval M. Irinotecan drug-eluting beads chemoembolization (DEBIRI) plus mFolfox 6 as front-line treatment in patients with non resectable liver dominant metastases of colorectal cancer (FFCD 1201 phaseII trial): result of single-arm, open-label Phase II study. JVIR S29 (2019). www.jvir.org/article/S1051-0443(18)31946-8/pdf

45. Bhutiani N, Akinwande O, Martin RCG. Efficacy and toxicity of hepatic intra-arterial drug-eluting (irinotecan) bead (DEBIRI) therapy in irinotecan-refractory unresectable colorectal liver metastases. World J. Surg. 40(5), 1178-1190 (2016).

46. Scevola G, Loreni G, Rastelli M, Sposato S, Ramponi S, Miele V. Third-line treatment of colorectal liver metastases using DEBIRI chemoembolization. Med. Oncol. 34(3), 37 (2017).

47. Fiorentini G, Sarti D, Nardella M et al. Chemoembolization alone or associated to bevacizumab for the therapy of colorectal cancer metastases (CRC): preliminary results of a randomized study. In vivo. In Press.

48. Schicho A, Hellerbrand C, Krüger K et al. Impact of different embolic agents for transarterial chemoembolization (TACE) procedures on systemic vascular endothelial growth factor (VEGF) levels. J. Clin. Transl. Hepatol. 4(4), 288-292 (2016).

49. Hartnell GG, Gates J, Stuart K, Underhill J, Brophy DP. Hepatic chemoembolization: effect of intraarterial lidocaine on pain and postprocedure recovery. Cardiovasc. Intervent. Radiol. 22(4), 293-297 (1999).

50. Fiorentini G, Aliberti C, Mulazzani L et al. Chemoembolization in colorectal liver metastases: the rebirth. Anticancer Res. 34(2), 575-584 (2014).

51. Glover C, Douse P, Kane P et al. Accuracy of investigations for asymptomatic colorectal liver metastases. Dis. Colon. Rectum 45(4), 476-484 (2002).

52. Niekel MC, Bipat S, Stoker J. Diagnostic imaging of colorectal liver metastases with CT, MR Imaging, FDG PET, and/or FDG PET/CT: a meta-analysis of prospective studies including patients who have not previously undergone treatment. Radiology 257(3), 674-684 (2010).

53. Jones RP, Stattner S, Dunne DF et al. Radiological assessment of response to neoadjuvant transcatheter hepatic therapy with irinotecan-eluting beads (DEBIRI) for colorectal liver metastases does not predict tumor destruction or long-term outcome. Eur. J. Surg. Onc. 39(10), 1122-1128 (2013).

54. Choi DJ, Kwak JM, Kim J, Woo SU, Kim SH. Preoperative chest computerized tomography in patients with locally advanced mid or lower rectal cancer: its role in staging and impact on treatment strategy. J. Surg. Oncol. 102(6), 588-592 (2010).

55. Kinkel K, Lu Y, Both M, Warren RS, Thoeni RF. Detection of hepatic metastases from cancers of the gastrointestinal tract by using noninvasive imaging methods (US, CT, MR imaging, PET): a meta-analysis. Radiology 224(3), 748-756 (2002).

56. Glazer ES, Beaty K, Abdalla EK, Vauthey JN, Curley SA. Effectiveness of positron emission tomography for predicting chemotherapy response in colorectal cancer liver metastases. Arch. Surg. 145(4), 340-345 (2010).

57. Miller AB, Hoogstraten B, Staquet M, Winkler A. Reporting results of cancer treatment. Cancer 47(1), 207-214 (1981).

58. Therasse P, Arbuck SG, Eisenhauer EA et al. New guidelines to evaluate the response to treatment in solid tumors.European Organization for Research and Treatment of Cancer, National Cancer Institute of the United States, National Cancer Institute of Canada. J. Nat. Cancer Inst. 92(3), 205-216 (2009).

59. Eisenhauer EA, Therasse P, Bogaerts J et al. New response evaluation criteria in solid tumours: revised RECIST guideline (version 1.1). Eur. J. Cancer 45(2), 228-247 (2009).

60. Zacharias AJ, Jayakrishnan TT, Rajeev R et al. Comparative effectiveness of hepatic artery based therapies for unresectable colorectal liver metastases: a meta-analysis. PLoS ONE 10(10), e0139940 (2015).

61. Wáng YJ, De Baere T, Idée JM, Ballet S. Transcatheter embolization therapy in liver cancer: an update of clinical evidences. Chin. J. Cancer Res. 27(2), 96-121 (2015). 
62. Lencioni R, Llovet JM. Modified RECIST (mRECIST) assessment for hepatocellular carcinoma. Semin. Liver Dis. 30(1), 52-60 (2010).

63. Gillmore R, Stuart S, Kirkwood A et al. EASL and mRECIST responses are independent prognostic factors for survival in hepatocellular cancer patients treated with transarterial embolization. J. Hepatol. 55(6), 1309-1316 (2011).

64. Lewis AL, Holden RR, Chung ST et al. Feasibility, safety and pharmacokinetic study of hepatic administration of drug-eluting beads loaded with irinotecan (DEBIRI) followed by intravenous administration of irinotecan in a porcine model. J. Mater. Sci. Mater. Med. 24(1), 115-127 (2013).

65. Martin RC, 2nd, Scoggins CR, Tomalty D et al. Irinotecan drug-eluting beads in the treatment of chemo-naive unresectable colorectal liver metastasis with concomitant systemic fluorouracil and oxaliplatin: results of pharmacokinetics and Phase I trial. J. Gastrointest. Surg. 16(8), 1531-1538 (2012).

66. Pernot S, Artru P, Mithieux F et al. Complete pathological response of unresectable liver metastases from colorectal cancer after trans-arterial chemoembolization with drug-eluting beads loaded with irinotecan (DEBIRI) and concomitant systemic FOLFOX: a case report from the FFCD 1201 trial. Clinics Res. Hepatol. Gastroenterol. 39(6), e73-e77 (2015).

67. Kekez D, Badzek S, Prejac J et al. Fluorouracil, leucovorin and irinotecan combined with intra-arterial hepatic infusion of drug-eluting beads preloaded with irinotecan in unresectable colorectal liver metastases: side effects and results of a concomitant treatment schedule. Clinical investigation. Tumori 100(5), 499-503 (2014).

68. Di Noia V, Basso M, Marsico V et al. DEBIRI plus capecitabine: a treatment option for refractory liver-dominant metastases from colorectal cancer. Future Oncol. 15(20), 2349-2360 (2017).

69. Akinwande O, Miller A, Hayes D, O’Hara R, Tomalty D, Martin RC. Concomitant capecitabine with hepatic delivery of drug eluting beads in metastatic colorectal cancer. Anticancer Res. 34(12), 7239-7245 (2014).

70. Huppert $\mathrm{P}$, Wenzel T, Wietholtz H. Transcatheter arterial chemo-embolization (TACE) of colorectal cancer liver metastases by irinotecan-eluting microspheres in a salvage patient population. Cardiovasc. Interventional Radiol. 37(1), 154-164 (2014).

71. Narayanan G, Barbery K, Suthar R, Guerrero G, Arora G. Transarterial chemoembolization using DEBIRI for treatment of hepatic metastases from colorectal cancer. Anticancer Res. 33(5), 2077-2083 (2013).

72. Vogl TJ, Lahrsow M, Albrecht MH et al. Survival of patients with non-resectable, chemotherapy-resistant colorectal cancer liver metastases undergoing conventional lipiodol-based transarterial chemoembolization (cTACE) palliatively versus neoadjuvantly prior to percutaneous thermal ablation. Eur. J. Radiol. 102, 138-145 (2018). 